\title{
Ter estado resultante não é ter construção resultativa: predicados secundários pseudo- resultativos e orações adjuntas de resultado no português brasileiro*
}

Having a resultant state is not the same as having resultative constructions: pseudo-resultative secondary predicates and adjunct result clauses in Brazilian

Portuguese

\author{
Julio William Curvelo Barbosa \\ (Universidade Estadual do Paraná, Paranaguá, Paraná, Brasil)
}

\section{RESUMO:}

O objetivo deste artigo é retomar a discussão na literatura acerca da presença de construções resultativas no português brasileiro. Este trabalho defende a hipótese de que não existam equivalentes sintáticos - e, consequentemente, semânticos - às construções resultativas nessa língua. Para justificar essa proposta, será demonstrado que línguas com emoldurações diferentes (framing, cf.: Talmy 2000, 2009, 2012) licenciam construções diferentes. Ademais, ao contrário das construções

\footnotetext{
* Este artigo apresenta os resultados de um trabalho apresentado no III Colóquio Brasileiro de Morfologia, na Universidade de São Paulo. Agradeço ao GREMD-USP, a Ana Paula Scher, Aline Rodero-Takahira, Esmeralda Negrão, Evani Viotti, Filomena Sandalo, Janayna Carvalho, João Paulo Cyrino, Luciana Storto, Marcello Modesto, Maria José Foltran, Paula Armelin, Rafael Minussi e Vitor Nóbrega, bem como a audiência do III CBM pelas sugestões, indicações bibliográficas e comentários em versões preliminares deste trabalho, cujas ideias centrais já vinham sendo debatidas (e rebatidas) desde 2005. Agradeço também aos pareceristas anônimos que avaliaram este trabalho, cujas contribuições foram extremamente valiosas para organizar a argumentação presente na versão final deste artigo. Apesar das inúmeras contribuições, ressalto que todos os erros remanescentes são de minha integral responsabilidade.
} 
defendidas como resultativas no português brasileiro, construções resultativas genuinas correspondem somente a contextos em que o verbo denota modo/maneira, e o estado resultante da ação é expresso por um predicado secundário, parte de um domínio mono-oracional ( $v P$ ).

Palavras-chave: Construções resultativas. Predicados secundários. Gramática Gerativa. Português brasileiro.

\begin{abstract}
:
This paper's goal is to resume the discussion on the literature surrounding the presence of resultative constructions in Brazilian Portuguese. This work defends the hypothesis that there are no syntactic - and, consequently - semantic equivalents in that language. In order to justify this proposal, it will be shown that languages with distinct framings (cf.: Talmy 2000, 2009, 2012) license distinct constructions. Moreover, unlike the constructions defended as resultatives in Brazilian Portuguese, genuine resultative constructions correspond only to contexts in which the verb denotes manner, and the resultant state is expressed by a secondary predicate, part of a single clause domain $(v P)$.
\end{abstract}

Key words: Resultative constructions. Secondary predicates. Generative Grammar. Brazilian Portuguese.

\title{
1. Introdução
}

Este artigo tentará contribuir para a discussão na literatura sobre as construções resultativas e sua existência no português brasileiro (doravante PB). Neste trabalho, é sugerido que os dados do PB debatidos na literatura formem duas classes distintas, com base em suas propriedades sintáticas. O primeiro grupo é o das construções pseudo-resultativas, cujos predicados secundários são modificadores do estado resultante, e não os responsáveis por denotar esse estado. O segundo grupo é o das orações adjuntas de resultado (doravante OARs), uma estrutura mais complexa sintaticamente - compondo uma estrutura com dois sintagmas verbais diferentes -, que aparenta ter as mesmas propriedades de evento das construções resultativas. Apesar disso, o trabalho argumentará que tais dados não são construções resultativas genuínas ${ }^{1}$, mas

1. Neste trabalho, a expressão (construção) resultativa genuína diz respeito aos dados consagrados na literatura como fenômeno linguístico recorrente e produtivo em línguas germânicas, e.g., inglês, alemão e holandês. 
apenas um resultado das configurações de emolduração de evento (cf.: Talmy 2000) aplicada em uma estrutura bi-oracional. Resultativas genuínas são, de acordo com a hipótese a ser defendida neste artigo, estruturas mono-oracionais com um verbo que carrega informações semânticas de modo/maneira, e um predicado secundário que denota o estado resultante, obtido pela ação do verbo sobre o objeto da sentença.

O artigo está organizado da seguinte maneira: na seção 2, apresentam-se os dados tradicionalmente analisados sobre construções resultativas do inglês, e as contrapartes do PB discutidas na literatura. A seção 3 debate a motivação empírica e os critérios definidores dessas construções no PB. A seção 4 apresenta argumentos empíricos para excluir pseudo-resultativas como equivalentes das resultativas do inglês, e investiga a equivalência semântica entre OARs no PB e resultativas do inglês. A seção 5 exclui as OARs como equivalentes sintáticas das resultativas, e apresenta uma análise para os dados do inglês e do PB. A seção 6 do artigo traz evidência independente para o critério da mono-oracionalidade com construções seriais resultativas (Sandalo 1995, Stewart 1998) - estruturas com dois verbos em que um deles atua como predicado secundário que denota o estado resultante da ação, traço característico de línguas emolduradas pelos satélites (Talmy 2009, 2012). A seção 7 traz as considerações finais.

\section{As construções resultativas e os dados do PB: observações iniciais}

Existe um debate duradouro e produtivo acerca da existência de construções resultativas no $\mathrm{PB}$, especialmente nas duas últimas décadas. A origem desse debate surge com a menção da sentença em (1), em Bisol (1975), nomeada pela autora como construção $V^{2}$. Porém, o primeiro trabalho a sugerir um paralelo entre esse tipo de dado do PB e as construções resultativas é Foltran (1999:41): "A construção $\mathrm{V}$ parece se aproximar do que normalmente se trata de predicado secundário resultativo".

(1) Deus criou os homens fracos.

(Bisol 1975:55)

A partir da aproximação feita em Foltran (1999), seguiram-se vários trabalhos com posicionamentos e argumentação distintos sobre dados semelhantes, tomando pontos de vista sintáticos, semânticos ou ambos. Essa discussão tem continuidade em Marcelino (2000, 2014), Lobato (2004), Ilari (2006), Leite (2006), Rech (2007), Barbosa (2008, 2009), Knöpfle (2010, 2014), Oliveira; Souza (2012), Oliveira (2013, 2014), Bertucci (2014), entre outros. Nos trabalhos citados, há uma clara divisão de pontos de vista; enquanto Foltran

2. O nome da construção se dá em referência ao número 5, em algarismos romanos. 
(1999), Marcelino (2000, 2014), Lobato (2004), Ilari (2006), Leite (2006) e Bertucci (2014) defendem que exista algum tipo de construção resultativa (semântica ou sintática) em PB, os trabalhos de Rech (2007), Barbosa (2008, 2009), Knöpfle (2010, 2014), Oliveira; Souza (2012) e Oliveira (2013, 2014) advogam pela impossibilidade de ocorrência do fenômeno nessa língua.

Antes de discutir os dados do PB, porém, cabe apresentar um pequeno conjunto de construções resultativas prototípicas apresentadas na literatura. Sua ocorrência em inglês permeia verbos transitivos (2), inergativos (3)-(4) e inacusativos (5). Ademais, uma definição consensual das características principais das resultativas é dada em (6), abaixo.
(2) The silversmith pounded the metal O ferreiro bateu o metal
flat. plano.

'O ferreiro bateu (com algo pesado/com força) no metal até ele ficar plano/deixou o metal plano batendo nele (com algo pesado/com força)'.

(Levin; Rappaport-Hovav 1995:50)

(3) The sopranos sang us sleepy As sopranos cantaram nós (acus.) sonolentos/com sono 'As sopranos cantaram até nos deixarem com sono/nos deram sono cantando'.

(Hoekstra 1988:116)

(4) She laughed him out of his patience.

Ela riu ele fora de sua (masc.) paciência

'Ela riu até tirar ele do sério/Ela tirou ele do sério rindo'.

(Hoekstra 1988:115)

(5) The curtain rolled open on the court.

A cortina rolou aberta em a quadra

'A cortina rolou na quadra até ficar aberta/A cortina (se) abriu rolando na quadra'.

(Landau 2003:2)

(6) "Um sintagma resultativo é um XP que denota o estado atingido pelo referente do NP do qual ele é predicado como um resultado da ação denotada pelo verbo na construção resultativa"”.

(Landau 2003:1)

Adicionalmente, há outras propriedades associadas ao fenômeno na vasta literatura sobre o assunto, apresentadas em (7), abaixo.

3. "A resultative phrase is an XP that denotes the state achieved by the referent of the NP it is predicated of as a result of the action denoted by the verb in the resultative construction". 
(7) Propriedades tradicionalmente associadas às construções resultativas

(a) Verbo causa uma mudança de estado no objeto (Simpson 1983; cf.: (2)-(4), acima, (31)-(34), abaixo);

(b) Resultado da ação do verbo sobre o objeto é denotado pelo sintagma adjetival/preposicional (Simpson 1983; cf.: (2)-(5), acima, (31)-(34), abaixo);

(c) Evento denotado pela sentença é um accomplishment (Hoekstra 1988; cf.: (2)-(5), acima, (41)-(42), abaixo);

(d) Objeto das resultativas nem sempre é objeto "verdadeiro" do verbo (Hoekstra 1988, cf.: (3)-(4), acima);

(e) Relação de predicação secundária - small clause (Simpson 1983, Hoekstra 1988, Mateu; Rigau 1999, Mateu 2000, 2001) ou predicado complexo (Carrier; Randall 1992, Levin; Rappaport Hovav 1995, Rothstein 2000, Neeleman; van de Koot 2002).

Partindo desse conjunto de propriedades para a observação dos dados apresentados nos trabalhos sobre as resultativas no PB, conclui-se que os dados dessa língua são mais variados, e podem ser divididos em dois grupos, nomeados da seguinte maneira: (i) construções com predicados secundários pseudo-resultativos ((8)-(19)) e construções com OARs ((20)-(22)):

(8) Ela cortou o cabelo curto.

(9) Ela costurou a saia justa.

(10) Ele fabricou a cadeira torta.

(11) Ele cortou o pão em fatias.

(Foltran 1999:190)

(12) O engenheiro construiu a ponte bem sólida.

(13) Deus criou os homens fracos, fracos.

(14) João pintou a casa bem amarelinha.

(15) O rio congelou solidíssimo/bem sólido/sólido, sólido.

(Lobato 2004:152-168)

(16) João quebrou o vidro EM PEDAÇOS.

(17) Maria assou o bolo SOLADO.

(Leite 2006:13)

(18) A cozinheira bateu [o bife bem batidinho].

(19) Joana picou o [papel bem picadinho].

(20) Ele andou [até gastar os sapatos].

(Marcelino 2000:2-53) 
(21) João martelou a lata até achatar.

(22) Maria esfregou o chão até brilhar.

(Bertucci 2014:625)

Os dados acima são assim divididos porque, enquanto estruturas pseudoresultativas (8)-(19) são compatíveis com os critérios (a) ${ }^{4},(\mathrm{c})$ e (e), em (7), os dados contendo OARs (20)-(22) são compatíveis apenas com a propriedade (7) a, acima ${ }^{5}$.

Dada tal disparidade entre esses dados, e por ainda não haver consenso sobre o verdadeiro status dos dados do PB perante a definição tradicional do que seja uma construção resultativa, o objetivo deste trabalho é apresentar argumentos contra a equivalência entre o fenômeno visto em línguas como o inglês, demonstrando que os dados do $\mathrm{PB}$ não se enquadram nesse tipo de fenômeno - no caso dos dados de (8)-(19), semanticamente e sintaticamente, e, nos casos de (20)-(22), sintaticamente.

\section{Justificando o debate: existem "construções" resultativas no PB?}

Ilari (2006) faz uma crítica detalhada às propostas de Lobato (2004), questionando os critérios de definição da autora, em especial a equivalência entre os dados do PB apresentados em (12)-(15), acima, e o fenômeno da construção resultativa como descrita na literatura sobre o fenômeno nas línguas germânicas. O autor parte da pergunta "o que é uma construção sintática?", e oferece três alternativas para lidar com as "resultativas do PB" de Lobato (op. cit.):

(23) "Como equivalente distribucional:

"Dificilmente alguém questionaria que a voz passiva seja uma construção sintática do português (...) Harris entendia que há transformação quando duas seqüências diferentes de morfemas podem ser encontradas no mesmo ambiente distribucional ou, mais precisamente, quando, num mesmo corpus encontramos indiferentemente uma ou outra seqüência ladeada por seqüências maiores que são exatamente iguais:

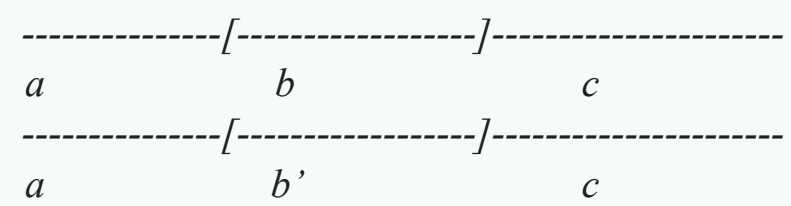

4. Nem todos os verbos de (8)-(19) efetuam uma mudança de estado no objeto, já que alguns são verbos de criação. Para uma discussão das propriedades desses verbos, cf.: Lobato (2004) e Barbosa (2008). 
(...)é fácil perceber que o falante dispõe de uma alternativa: topicalizar ou não, alçar ou não, deslocar ou não, realizar ou não o objeto pronominal como um segmento. Infelizmente, falar em escolha não serve no caso das construções resultativas, porque não parece possível escolher entre uma construção resultativa e uma não resultativa como se as duas alternativas fossem realmente equivalentes "para efeito do texto maior"'"'

(Ilari 2006:11-12)

(24) "Como bloco, ou "seqüências lineares de unidades que, pelo menos para certos efeitos, podem ser analisadas como um todo" (Ilari 2006:12), ou como "seqüência de expressões que é reconhecida como um todo para efeito de aplicação de uma operação sintática ou semântica."

(Ilari 2006:13).

Observando os dados de Lobato como (12)-(15), acima, Ilari (2006) sugere que as características apresentadas pela autora para definir tais dados como representativos de construções resultativas no $\mathrm{PB}$ não se enquadram às definições em (23)-(24). Ilari apresenta um argumento empírico forte para isso - a dificuldade em distinguir o escopo do adjunto de tempo em contextos diferentes, já que predicativo (25), adjunto adnominal (26) e adjunto adverbial (27), abaixo, têm todos o mesmo comportamento sintático. Portanto, os predicados secundários presentes nos dados do PB não apresentariam qualquer caráter idiossincrático se contrastados aos dados do inglês, formadores de uma "construção" - especialmente (3) e (4), acima.

(25) A panela solar "Hélios" da Tabajara Tech cozinha o ovo pochê em 7 minutos e duro em 45.

(26) A panela solar "Hélios" da Tabajara Tech cozinha o ovo de galinha em 7 minutos e o de ganso em 13.

(27) A panela solar "Hélios" da Tabajara Tech cozinha o ovo de galinha à perfeição/perfeito em 7 minutos e o de ganso em 13.

(Ilari 2006:13)

Apesar disso, restaria uma terceira alternativa:

(28) Como conjunto de critérios cruciais:

"Em resumo, na construção resultativa, (a) há formação de predicado complexo, com predicação do predicado secundário sobre o objeto e não sobre proposição; (b) há atribuição de nova propriedade ao referente do objeto por efeito da ação verbal e (c) há interpretação do evento como télico (isto é, delimitado)."

(Lobato 2004:147, apud Ilari 2006:13-14) 
Contrário à proposta de Lobato (op. cit.), Ilari refuta a afirmação de que PB possua construções resultativas, já que critérios para determinar uma construção deveriam ser sintáticos, e não (exclusivamente) semânticos:

[...] as condições de que [Lobato] se vale em sua definição são semânticas desde o começo, ou pelo menos híbridas. Esse caráter semântico/híbrido se traduz na impossibilidade [de] reduzir a uma natureza estritamente sintática conceitos como "referente [do objeto do verbo]", "interpretação", "evento" e "télico". (Ilari 2006:14, grifo meu)

Apesar das criticar os critérios de Lobato (2004) para classificar os dados do PB como resultativas genuínas, Ilari (2006) aponta outras formas que indicariam resultado - com usos de em e até (cf.: (11), (16), (20)-(22), acima).

Em um primeiro momento, pode-se dizer que a conclusão de Ilari em (28), acima, seja parcialmente verdadeira. Idealmente, seria desejável definir fenômenos sintáticos sintaticamente, e definições baseadas apenas na semântica poderiam a soar estipulativas (cf.: (6), acima). Por outro lado, isso não significa que todas as definições semânticas de resultatividade presentes nos trabalhos sobre o PB que defendem os dados de (8)-(22) estejam incorretas, ou que apenas definições sintáticas possam trazer respostas adequadas para as hipóteses formadas. Assim, a intenção deste trabalho não é deslegitimar as demais propostas feitas para o $\mathrm{PB}$, mas mostrar que elas são abrangentes demais, e não lidam com o fenômeno construção a partir de critérios que sejam, ainda que não completamente sintáticos, mais sintáticos que semânticos.

Parte do impasse acerca da existência de construções resultativas no PB se dá pela complicação das definições do fenômeno. Esses problemas advêm da questão terminológica e, essencialmente, da má-aplicação do conceito de construção ${ }^{6}$. Afinal, a dificuldade em se delimitar o que é (ou não) uma construção resultativa está em determinar uma separação entre o que é o fenômeno sintático chamado de construção resultativa, característico de línguas germânicas como o inglês, e outras maneiras de denotar um estado resultante da ação verbal - estas, sim, ocorrendo em línguas como o PB. A hipótese deste trabalho concentra-se na seguinte ideia:

(29) Definição sintática das construções resultativas genuínas Construções resultativas são estruturas mono-oracionais e transitivas (vPs), formadas por um verbo que denota o modo da ação, um objeto direto afetado pela ação verbal (tema), e um predicado secundário que acrescenta à estrutura o estado resultante e a telicidade da ação. 
Em suma: denotar estado resultante ou indicar resultado da ação não significa necessariamente que uma língua seja capaz de denotar algo semelhante a uma construção resultativa. Todavia, dados com verbos canonicamente inergativos, como (3) e (4), acima, evidenciam que uma construção resultativa não é produto de mero acréscimo do predicado secundário sobre uma ação verbal. Construções resultativas são um fenômeno diferente dos recursos que uma língua como o PB possui para descrever essa estrutura de evento.

É baseando-se nessa premissa que este trabalho se norteia. Uma construção resultativa não é mero epifenômeno, mas uma estrutura sintática específica, com consequências tipológicas/paramétricas, especialmente em como traços semânticos que denotam estado resultante e modo/maneira são codificados sintaticamente. Na próxima seção, apresentam-se argumentos contra a equivalência sintática e semântica das resultativas do inglês e pseudoresultativas.

\section{4. (De)limitações terminológicas e a interface sintaxe/semân- tica}

\subsection{As construções pseudo-resultativas: desconstruindo um mito}

Assim como Ilari (2006), Barbosa (2008) tenta fazer uma classificação mais sintática dos dados do PB. As estruturas aqui chamadas de pseudoresultativas como os em (8)-(19), acima, não seriam equivalentes às resultativas do inglês porque os predicados do PB não denotariam o estado resultante, mas modificariam o estado resultante já presente no par verbo+objeto. Evidências para tal afirmação são apresentadas pelos testes a seguir, que mostram que os dados do PB são incompatíveis com as propriedades descritas na literatura (cf.: (7), acima).

Hoekstra (1988:130) menciona que nem todo verbo pode se combinar a um NP e gerar um estado resultante. Porém, alguns podem formar uma construção resultativa. Como no inglês, um verbo do holandês como lopen ('andar'), geralmente inergativo, sofre uma alteração em suas propriedades de seleção argumental quando envolvido em uma construção resultativa como em (30), abaixo ${ }^{7}$.

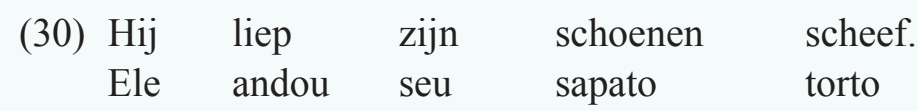

'Ele andou até deixar os sapatos gastos de um lado/gastou o sapato de um lado andando'.

(Hoekstra 1988:115)

7. Para Hoekstra (1988), o verbo lopen seleciona uma SC resultativa $\left[{ }_{\mathrm{SC}}\left[{ }_{\mathrm{NP}} \mathrm{schoenen}_{[}\right]\left[_{\mathrm{AP}} \mathrm{scheef}\right]\right]$, complemento do verbo. 
Consequentemente, observar o comportamento dos elementos que aparecem após o verbo nos dados do PB e em línguas como o inglês nos permite identificar resultativas genuínas. O primeiro teste apresentado é o de acarretamento, que permite mostrar que as propriedades (7)a-b, acima, não estão presentes nas pseudo-resultativas do PB. O teste proposto por Levinson (2006) permite identificar construções que a autora chama de pseudo-resultativas no inglês. A autora argumenta que, ao contrário das resultativas (cf.: (31), abaixo), a ação do verbo das pseudo-resultativas não causa um estado resultante no objeto que passa a ser denotado pelo adjetivo. Ao invés disso, a ação de um verbo como braid (trançar) cria um objeto (trança) - o elemento modificado de fato pelo predicado secundário (cf.: (32), abaixo):

(31) a. Mary hammered the metal flat. 'Mary martelou o metal plano.'

b. The metal is flat. 'O metal está plano.'

(32) Mary braided her hair tight. $\rightarrow$ Mary's hair is tight. 'Mary trançou seu cabelo firme' $\rightarrow$ O cabelo da Mary está firme.'

(Levinson 2006:2-3)

Barbosa (2008) mostra o mesmo contraste nos dados do PB (cf.: (33)-(36), abaixo). No PB, o acarretamento entre a ação e o estado resultante sobre o objeto não se sustenta, assim como as pseudo-resultativas do inglês. Isso ocorre porque a maioria dos verbos das pseudo-resultativas são verbos de criação, portanto, incapazes de realizar uma ação sobre um objeto que gere um estado resultante dessa ação.

(33) John hammered the metal flat.

$\rightarrow$ The metal was hammered.

$\rightarrow$ The metal got flat.

('O metal foi martelado')

('O metal ficou achatado')

$\rightarrow$ The metal was flattened.

('O metal foi achatado')

(34) Mary laughed Bill out of his patience.

$\rightarrow$ Bill was laughed at.

('Riram de Bill')

$\rightarrow$ Bill got out of his patience. ("Bill "saiu do sério")

$\rightarrow$ Bill was put out of his patience ("Bill foi "tirado do sério"')

(35) João pintou a casa bem amarelinha.

$\rightarrow$ A casa foi pintada.

$\rightarrow$ A casa ficou bem amarelinha.

$\rightarrow$ ??A casa foi amarelada.

(36) Ele martelou o prego torto.

$\rightarrow$ O prego foi martelado. 
Ter estado resultante não é ter construção resultativa: predicados secundários pseudo-resultativos e orações adjuntas de resultado no português brasileiro

$\rightarrow$ O prego ficou torto.

$\rightarrow$ ??O prego foi entortado.

(Barbosa 2008:63-64)

Outro teste que evidencia a diferença entre $\mathrm{PB}$ e inglês quanto à propriedade (7)c, acima, diz respeito ao comportamento aspectual das construções resultativas em comparação às pseudo-resultativas. Seguindo Vendler (1957, 1967), os trabalhos sobre as resultativas afirmam que essas construções são télicas, independentemente do verbo. O verbo inergativo lopen ('andar') no holandês, (cf:: (30), acima), denota uma atividade - ou seja, é um predicado atélico. Consequentemente, em uma sentença intransitiva, o modificador que indica telicidade over een uur ('em uma hora') não é gramatical (cf.: (37), abaixo). Porém, na construção resultativa o teste se inverte - a sentença é télica, e passa a não aceitar o modificador atélico voor een uur ('por uma hora'; cf.: (38), abaixo):

(37) Hij liep voor een uur/ *over een uur. Ele andou por uma hora em uma hora 'Ele andou por uma hora/*em uma hora'.

(38) Hij liep zijn schoenen scheef over een uur/ *voor Ele andou seu sapato torto em uma hora por een uur. uma hora

'Ele andou até deixar os sapatos gastos de um lado/gastou o sapado de um lado andando em uma hora/*por uma hora'.

Em consonância com o fato acerca das propriedades verbais das construções pseudo-resultativas do PB mencionadas no teste anterior - verbos de criação não afetam seus objetos, mas os criam - é possível notar que os dados mencionados como resultativas do $\mathrm{PB}$ já possuem um ponto final na escala aspectual, ou seja, são accomplishments, mesmo sem a presença do predicado secundário ((39), (40)), ao contrário das resultativas do inglês - mesmo as transitivas, como é possível notar em (41)-(42), abaixo.

(39) Ele cortou o cabelo (curto) em cinco minutos/??por cinco minutos.

(40) Ele desenhou o círculo (torto) em cinco minutos/*por cinco minutos.

(41) John hammered the metal *in an hour/ for an hour.

(42) John hammered the metal flat in an hour $/ *$ for an hour.

(cf.: Rech 2007:88)

Esse teste mostra que não é a presença do predicado secundário que introduz telicidade ou resultado nas sentenças do PB - afinal, estas já possuem um estado resultante quando verbo e objeto direto se combinam. Se há estado resultante na ação do verbo sem a presença do predicado secundário, a característica 
(7)c, acima, não se aplica aos dados do PB pelo mesmo motivo do inglês, a característica (7)b, acima.

Outra característica das resultativas é diagnosticada em Kratzer (2004): resultativas com verbos inergativos no alemão não permitem que o resultado da ação seja a resposta para uma pergunta de modo da ação, feita com wie ('como') (44). Segundo Kratzer, verbos inergativos formam resultativas genuínas (cf.: (7)d, acima). Assim, dados com verbos transitivos seriam exemplos de leitura adverbial desses adjetivos em alemão (cf.: (45)-(46), abaixo) ${ }^{8}$. Ainda que na literatura sobre o PB não haja construções com verbos inergativos consideradas resultativas 9 , o teste aplicado aos dados com verbos transitivos no PB mostra que os resultados são compatíveis com as "resultativas adverbiais" do alemão, e não com resultativas genuínas (cf.: (47)-(50)a, abaixo, (7)b, acima).
(43) Er hat seine Familie magenkrank gekocht. Ele tem sua família estômago doente cozinhado 'Ele deixou sua família doente com o que ele cozinhou.'
(44) *Wie hat er seine Familie gekocht (Magenkrank.) Como tem ele sua família cozinhado (estômago doente.)
(45) Sie haben *(den Fußballplatz) beleuchtet. Eles têm o campo de futebol iluminado. 'Eles iluminaram o campo de futebol'.
(46) Wie soll ich den Fußballplatz beleuchten? Hell. Como devo eu o campo de futebol iluminar Brilhante 'Como eu devo iluminar o campo de futebol? Brilhante'.

(Kratzer 2004:2-11)
(47) Como ela cortou seu cabelo? Curto.
(48) Como ele desenhou o círculo? Torto.
(49) Como ela deve costurar a saia? Justa.
(50) Como ele fabricou a cadeira? Torta.

(Rech 2007:87)

Em (47)-(50), fica nítido que a presença do predicado secundário não é a de um introdutor de resultado da ação, já que apresenta uma função adverbial de modo da ação. É fundamental lembrar desse contraste entre modo e estado resultante, que será retomado na seção 5 .

8. Assim como no alemão, a leitura adverbial também não ocorre nas resultativas do inglês:

(i) How did he hammer the nail? (*flat) (slowly/rapidly) (Marcelino 2007:51)

(ii) *How did John hammer the metal? Flat. ${ }^{*}$ Como John martelou o metal? Chato. (Bertucci 2014:631)

9. Cabe notar que essa afirmação vale, ao menos, para os casos das sentenças aqui denominadas como pseudo-resultativas. Uma discussão de construções com verbos inergativos se dá na próxima seção, com os dados das OARs. 
Outro teste envolve as camadas estruturais envolvidas nas construções resultativas. Resultativas permitem leitura restitutiva do advérbio (Beck 2005, cf.: (51), abaixo), mas não no PB (cf.: (52), abaixo). Isso garante a presença de dois níveis de predicação. $\mathrm{O}$ primeiro diz respeito à predicação do verbo sobre o objeto, em uma relação de causa - compatível com uma leitura repetitiva, que pode ser interpretada como a realização da ação verbal de maneira consecutiva. O segundo nível é visto pela predicação do predicado resultativo sobre o objeto, denotando o estado resultante atingido pela ação verbal - compatível com a leitura restitutiva, em que o estado resultante é restaurado por uma única ação, denotada pelo verbo.

(51) a. Sally hammered the metal flat again.

b. Sally hammered the metal flat, and the metal had been hammered flat before.

c. Sally hammered the metal flat, and the metal had been flat before.

(Restitutiva)

(52) a. João pintou a casa bem amarelinha novamente.

b. João pintou a casa bem amarelinha, e a casa já havia sido pintada bem amarelinha antes.

c. \#João pintou a casa bem amarelinha, e a casa já havia ficado bem amarelinha antes

Se os testes apresentados estiverem corretos, os dados do PB não denotam uma relação de estado resultante obtida pelo adjetivo. Isso bloquearia a leitura restitutiva, característica das relações de predicação secundária/small clauses sugeridas na literatura (cf.: (7)e, acima). Em (52), é impossível obter a leitura restitutiva - não é possível, a partir de (52)a, depreender que (52)c signifique algo como "a casa era bem amarelinha, mas tinha deixado de ser bem amarelinha; agora, João fez com que a casa ficasse bem amarelinha novamente porque ele a pintou ${ }^{10}$. A ausência da leitura restitutiva evidencia o caráter pseudo-resultativo dos dados do PB, já que não haveria uma camada distinta para ação e o estado resultante.

De acordo com os testes apresentados, fica claro que os dados do PB em (8)-(19), acima, tratam, inequivocamente, de outro tipo de formação sintática que não equivale às resultativas presentes nas línguas germânicas, e estão mais próximos das pseudo-resultativas de Levinson (2006). Esse resultado é compatível com a maioria das opiniões na literatura que defendem não haver construções resultativas no PB. Porém, os dados apresentados em (20)-(22),

10. A intuição dos falantes acerca de (52)c não é uniforme, e indica que predicados secundários como bem amarelinha são difíceis de ser interpretados pelos falantes, já que modificação de estado resultante parece não ser tão frequente quanto outros tipos de predicação secundária. O contraste ficará mais claro na seção 4.2. 
acima, são geralmente rotulados como equivalentes às resultativas do inglês. A próxima seção argumenta contra essa equivalência, dialogando com a proposta de Bertucci (2014).

\subsection{OARs e os variados tipos de expressão de estado resultante}

A seção anterior lidou com os dados das pseudo-resultativas, tema controverso na literatura sobre as construções resultativas. Porém, Marcelino (2000) e Bertucci (2014) mencionam exemplos de orações parafraseadas do inglês, classificados na seção 1 como OARs (cf.: (20)-(22), acima).

Em uma descrição extremamente detalhada, Bertucci (2014) traz uma análise semântica para o $\mathrm{PB}$, contrastando predicados resultativos do inglês como (53)-(54), abaixo, com as expressões do PB marcadas em (21)-(22), repetidas em (55)-(56):

(53) John hammered the metal flat.

'John martelou o metal até achatar/ficar achatado'

(54) They wiped the table clean.

'Eles passaram um pano na mesa até limpar/ficar limpa'

(55) João martelou a lata até achatar.

(56) Maria esfregou o chão até brilhar ${ }^{11}$.

(Bertucci 2014:625)

Bertucci (2014) se contrapõe a Barbosa (2008), indicando que existe equivalência semântica entre resultativas do inglês e os dados do PB em (55)(56), que o autor chama de resultativas infinitivas. Observando a semântica de eventos (Parsons 1990), Bertucci (2014) apresenta argumentos persuasivos para a equivalência semântica entre os dados do PB e do inglês, mostrando que as sentenças do PB apresentam a mesma distribuição dos operadores semânticos de causa, mudança de estado e estado resultante, do inglês, inclusive mantendo a delimitação do evento pelo predicado secundário, como nas resultativas genuínas.

Examinando os dados elencados por Bertucci (2014), caberia reaplicar os testes da seção 4.1. para determinar qual o grau de impacto sobre os critérios em (7), acima - claramente incompatíveis com as pseudo-resultativas - na estrutura sintática das resultativas infinitivas de Bertucci (2014).

Primeiramente, tanto os adjetivos flat e clean, em inglês, quanto os sintagmas até achatar e até brilhar denotam o estado resultante da ação. Isso significa que as atividades de martelar e esfregar em (55)-(56), acima, só continuam

11. Marcelino (2000) aborda dados semelhantes, porém sugere que eles não sejam representativos de construções resultativas no $\mathrm{PB}$, ao contrário de alguns predicados transitivos com semântica aspectual compatível (e.g., (12)-(15)), considerados pelo autor como contrapartes das resultativas transitivas do inglês. 
enquanto os estados até achatar e até brilhar, respectivamente, não tiverem sido plenamente atingidos. Além disso, paráfrases semelhantes às resultativas do inglês são possíveis, desde que haja um intensificador explícito, como de tanto ((57)b, (58)b):

(57) a. João martelou a lata até achatar b. João achatou a lata de tanto martelar (n)ela.

(58) a. Maria esfregou o chão até brilhar.

b. Maria fez o chão brilhar de tanto esfregar ele.

Em um primeiro momento, parece que expressões do PB com orações adjuntas infinitivas possuem - aparentemente - o mesmo comportamento sintático das resultativas genuínas. Isso se comprovaria por tais expressões apresentarem comportamento semelhante aos dados do inglês em alguns dos testes que identificaram pseudo-resultativas, como o teste de acarretamento:

(59) João martelou a lata até achatar.

$\rightarrow$ A lata foi martelada.

$\rightarrow$ A lata ficou achatada.

$\rightarrow$ A lata foi achatada.

(60) Maria esfregou o chão até brilhar.

$\rightarrow$ O chão foi esfregado.

$\rightarrow$ O chão ficou brilhando/*brilhado/lustrado ${ }^{12}$.

$\rightarrow$ O chão foi brilhando/*brilhado/lustrado.

Os dados de (55)-(56), acima, também aceitam expressões temporais télicas - a natureza aspectual do adjunto parece ser a mesma dos adjuntos temporais, já que introduz a telicidade no predicado:

(61) João martelou a lata até achatar em uma hora/*por uma hora.

(62) Maria esfregou o chão até brilhar em uma hora/*por uma hora.

Assim como resultativas genuínas, as resultativas infinitivas mencionadas em Bertucci (2014) não formam pares de pergunta/resposta com como (cf.: (63)(64), abaixo), em consonância com os dados do alemão (cf.: (43)-(44), acima) ${ }^{13}$ :

12. Um dos pareceristas menciona que o uso do gerúndio ("O chão ficou brilhando") não seria adequado para o teste em (60), pois seria incompatível com o uso do particípio nos testes (33)-(36) e (59). Além disso, o parecerista ressalta o (importante) fato de que brilhar não possui uma contraparte causativa, contrariamente a lustrar.

13. Um dos pareceristas questiona a agramaticalidade de (63) e (64), alegando que se um sujeito estiver expresso na resposta, o resultado passa a ser aceitável (em sua interpretação, já que os julgamentos aqui se contrapõem):

(i) Como o João martelou a lata? Até ela achatar.

(ii) Como a Maria esfregou o chão? Até ele brilhar

Uma possível explicação seria que o objeto alçado à posição de sujeito nessas sentenças força a interpretação da oração adjunta em uma estrutura de alternância causativo-incoativa, em que a relação entre as orações principais (João martelou a lata/Maria esfregou o chão) e suas respectivas orações 
(63) Como o João martelou a lata? *Até achatá-la.

(64) Como a Maria esfregou o chão? *Até (ele) brilhar.

Todavia, é interessante notar que, se o objeto do verbo infinitivo for alçado à posição de sujeito, a modificação télica deixa de ser possível (cf.: (65)-(66), abaixo) $)^{14}$ :

(65) João martelou a lata até ela achatar (*em uma hora).

(66) Maria esfregou o chão até ele brilhar (*em uma hora).

Tal comportamento serve como argumento para a hipótese defendida neste trabalho. Justamente pelo fato de a oração infinitiva ser um adjunto que introduz telicidade na estrutura, o acréscimo de outro adjunto télico causa essa incompatibilidade - logo, OARs não têm o mesmo estatuto dos predicados resultativos das línguas germânicas, já que nelas não há conflitos quanto à presença do predicado resultativo em companhia do adjunto télico em uma hora.

Os dados acima também apresentam distinção em relação ao inglês quanto a possibilidade de leitura restitutiva com novamente em alguns contextos, dependendo de onde se considera o objeto omitido na oração adjunta. A sentença em (67), abaixo, é ambígua quanto aos referentes da ação do verbo infinitivo. É possível depreender tanto a interpretação em (68)a, em que o sujeito participa da ação de achatar a lata - e, consequentemente, do escopo do advérbio novamente - quanto a interpretação em (69)a, em que o escopo do advérbio recai apenas sobre a ação de a lata ter sido/ficado achatada - possivelmente, por outra ação que não a de João a ter martelado. Com base nessas interpretações, pode-se dizer que a leitura restitutiva é incompatível com a interpretação em (68)a, abaixo, considerando que o objeto da oração infinitiva (ela) seja objeto de um verbo causativo com agente. Porém, no caso em que o verbo infinitivo não pressupõe a presença de um argumento externo e achatar é interpretado como uma instância de alternância causativa, como (69)a, acima, a leitura restitutiva se torna disponível - fato esperado, já que com um agente na oração infinitiva, configura-se outro domínio oracional. De modo semelhante, a leitura restitutiva também está disponível em (70), abaixo, já que o verbo brilhar não apresenta semântica causativa/agentiva ${ }^{15}$ :

adjuntas deixam de ter a mesma relação de causa e consequência - assim, o teste perderia seu valor. 14. Agradeço aos pareceristas que apontaram os fatos a seguir, bem como a repercussão da discussão acerca da alternância causativa nos demais testes a serem discutidos até o fim desta seção.

15. Vale notar que uma eventual leitura em que brilhar possa ser atribuído ao sujeito Maria (e.g., em que ficou com a testa suada pelo esforço e, consequentemente, brilhando) não será considerada aqui, por ser irrelevante para a discussão em pauta. 
(67) João martelou a lata até achatar novamente.

(68) a. João martelou a lata até ele achatá-la novamente.

b. João martelou a lata até achatá-la, e a lata já havia sido martelada até achatar pelo João antes.

(Repetitiva)

c. \#João martelou a lata até achatá-la, e a lata já havia ficado achatada antes

(Restitutiva)

(69) a. João martelou a lata até ela achatar novamente.

b. João martelou a lata até achatá-la, e a lata já havia sido martelada até achatar antes.

(Repetitiva)

c. João martelou a lata até (ela) achatar, e a lata já havia ficado achatada antes.

(Restitutiva)

(70) a. Maria esfregou o chão até (ele) brilhar novamente.

b. Maria esfregou o chão até brilhar, e o chão já havia sido esfregado até brilhar antes.

(Repetitiva)

c. Maria esfregou o chão até brilhar, e o chão já havia ficado brilhando antes.

(Restitutiva)

Considerando os testes acima, os dados em (55)-(56), acima, não parecem ser representativos do PB para construções resultativas como as das línguas germânicas, especialmente quando se consideram os argumentos da oração infinitiva. Esse ponto ajuda a decidir o real status das resultativas infinitivas de Bertucci (2014). Nitidamente, os contextos acima dizem respeito a um fenômeno sintático que envolve duas orações, ou dois sintagmas verbais. Apesar disso, considerar os dados em (55)-(56), como resultativas legítimas do PB traz dois problemas de ordem conceitual.

O primeiro problema é de disponibilidade estrutural: orações adjuntas fazem parte da gramática de qualquer língua. Logo, como se explica que nas demais línguas não se forma resultativas com essa estrutura sintática? O segundo problema será apresentado na próxima seção.

\section{Se não existem resultativas no $P B$, o que são as estruturas com semântica de resultado?}

Neste trabalho, assim como em Bertucci (2014), acredita-se que as OARs (ou resultativas infinitivas, para Bertucci 2014) apresentem equivalência semântica - ainda que parcial - às resultativas das línguas germânicas, ao menos perante os critérios mencionados até aqui. Porém, a discrepância sintática para o inglês traz consequências teóricas importantes.

Além da necessidade de se explicar por que construções resultativas só aparecem com essa estrutura em PB, equiparar OARs (ou resultativas infinitivas, segundo Bertucci 2014) às resultativas genuínas implica aceitar que uma mesma relação entre subeventos é expressa por mais de um tipo de estrutura. 
O problema é que uma argumentação em termos exclusivamente semânticos ainda não seria suficiente para garantir uma distinção adequada entre as construções resultativas e os dados do PB. Afinal, de acordo com os testes apresentados na seção 4.2., há divergências empíricas incompatíveis com a proposta de Bertucci (2014) - ou seja, não se pode garantir que as OARs sejam equivalentes semânticas indiscutíveis das resultativas genuínas - nem que essa equivalência seja suficiente para aproximar duas estruturas sintáticas claramente diferentes. Isso exigiria motivações particulares na escolha estrutural do PB em contraste com inglês e outras línguas germânicas, que formam predicados complexos/small clauses, característica distintiva de construções resultativas na literatura.

Por conta da necessidade de se explicar a falta de uniformidade nas propriedades apresentadas nos dados do PB em geral, além das disparidades estruturais entre os dados do PB em geral e as resultativas em línguas germânicas, este trabalho sugere que seja adotado um critério sintático como guia para a delimitação de uma construção resultativa genuína: a mono-oracionalidade. Ainda que argumente contra a presença de resultativas genuínas no PB, Barbosa (2008) também sugere critérios baseados em questões semânticas:

(71) Critério Resultativo Uma sentença é considerada uma construção resultativa desde que não viole qualquer das seguintes condições:

(i) $\mathrm{O}$ predicado secundário resultativo denota um estado resultante $(a P / P P)$;

(ii) $\mathrm{O}$ objeto atinge o estado resultante por meio de uma mudança de estado $(v+V)$;

(iii) A mudança de estado é denotada pelo predicado resultativo (e não pelo verbo, que denota o desencadeamento da mudança) ([modol maneira] em $v$ );

(iv) A mudança de estado é causada por um desencadeador externo ("agente");

(v) O verbo possui uma leitura causativa ("agente" como desencadeador da mudança de estado) (v);

(vi) O verbo explicita o modo pelo qual a mudança de estado é desencadeada ([modo/maneira $] \mathrm{em} v$ ).

(cf.: Barbosa 2008:33-34)

Apesar do viés exclusivamente semântico, os critérios de Barbosa (2008) têm origem na discussão iniciada em Mateu; Rigau (1999) e Mateu (2000, 2001), que levam em consideração a proposta de Talmy $(1985,1991)$ para os padrões de lexicalização de eventos nas línguas do mundo, baseados no conceito de padrão de emolduração (cf:: Talmy 1985, 1991, 2000). Padrões de emolduração preveem que, embora a concepção semântica dos eventos seja universal, alguns 
traços gramaticais sejam expressos de maneiras variadas na superfície - i.e., em posições sintáticas distintas - a depender da língua em questão.

De acordo com Talmy (op. cit.), eventos seriam divididos em duas grandes subcategorias: evento, geralmente representado pela oração matriz, e co-evento, expresso em predicados secundários e adjuntos. A variação entre as línguas se dá pela distribuição de algumas propriedades presentes na codificação sintática desses eventos, identificáveis a partir da observação translinguística dos fenômenos em questão.

Uma ilustração da variação na manifestação superficial dos traços do evento pode ser vista nas sentenças com verbos de movimento. Enquanto línguas como o inglês expressam os traços de modo/maneira da ação nos verbos de movimento (72), línguas como o espanhol (e o PB, por extensão) expressam a direção do movimento no que Talmy chama de satélites (73) - e.g., partículas e orações adjuntas. Por conta dessa distribuição, o autor defende que inglês seja uma língua emoldurada pelos satélites, enquanto o espanhol (e o PB, por extensão; cf.: Barbosa 2008, 2012) seria uma língua emoldurada pelo verbo.

(72) The bottle floated into the cave.

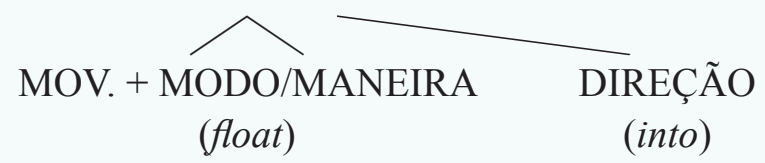

(73)

$\begin{aligned} & \text { La botella entró } \\ & \text { the bottle a la }\end{aligned}$
$\begin{gathered}\text { MOVED-in } \\ \text { (entró) }\end{gathered}$
to to the

'A garrafa boiou para dentro da caverna/entrou na caverna boiando'

(cf.: Barbosa 2008:47)

Barbosa (2008) estende essa distribuição dos traços, sugerindo que a diferença entre resultativas genuínas e pseudo-resultativas ocorre por conta de uma distribuição de traços análoga à dos verbos de movimento do espanhol, como a proposta de Talmy (2000), em que o estado resultante apareceria nos satélites das línguas germânicas, e nos verbos das línguas românicas:

(74) John hammered

'John [causou com marteladas]

$$
\text { CAUSA + MODO }
$$

the metal flat.

o metal [ficar achatado]'

ESTADO RESULTANTE

(Barbosa 2008:51) 
(75) João pintou
'João [causou_ficar pintada]
CAUSA + ESTADO RESULTANTE a casa bem amarelinha.

a casa [bem amarelinha]'

\section{MODO}

(cf.: Barbosa 2008:104)

Como Barbosa (2008, 2012), este trabalho sugere que o estado resultante nas resultativas do inglês seja denotado pelo predicado secundário (aP ou PP), por conta das características de emolduração dessa língua ${ }^{16}$. Em línguas como o inglês, quando o estado resultante é expresso pelo predicado secundário i.e., pelos satélites - o modo/maneira da ação é expresso pelo verbo. Essas propriedades são compatíveis com os critérios em (7) e (71), acima, que, por sua vez, podem ser convertidos em relações sintáticas, como (76):

(76) Representação estrutural das construções resultativas

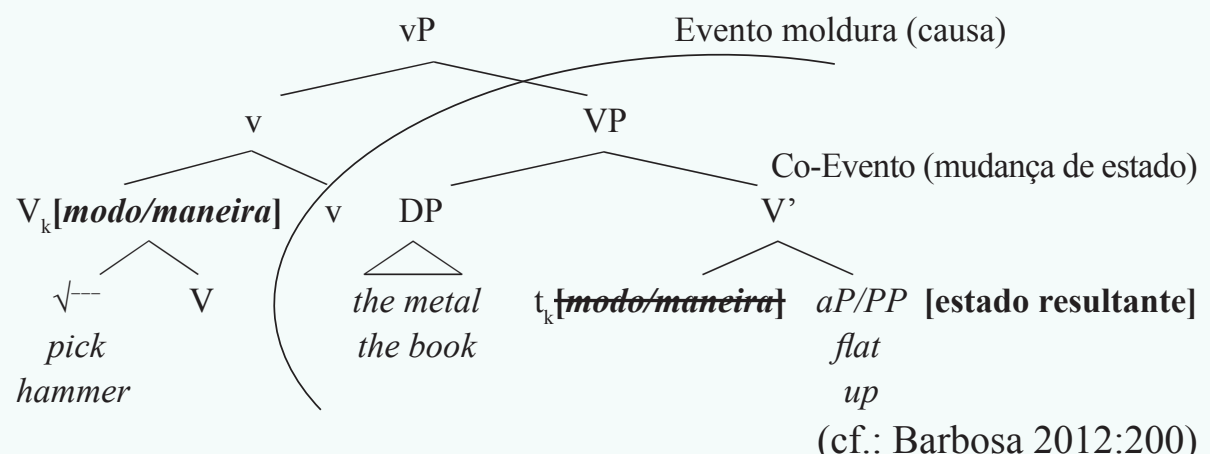

No caso do PB, língua emoldurada pelo verbo, sentenças pseudo-resultativas apresentariam um padrão de emolduração diferente do inglês (cf.: Barbosa 2008, 2012) - enquanto o predicado secundário denota o modo/maneira da ação (cf.: (47)-(50), acima), o VP (verbo+objeto) denota o estado resultante (cf.: inglês (40) versus PB (41), acima). A estrutura para sentenças pseudo-resultativas é vista em (77):

16. Para outros trabalhos que relacionam as propriedades tipológicas de Talmy à ocorrência de construções resultativas na Gramática Gerativa (mais especificamente, Hale; Keyser 1993, 1998), cf.: Mateu e Rigau (1999), Mateu (2000, 2001), Marcelino (2000, 2007). Para trabalhos que fazem o mesmo paralelo na Gramática Cognitiva, cf.: Leite (2006). 
(77) Representação estrutural das construções pseudo-resultativas

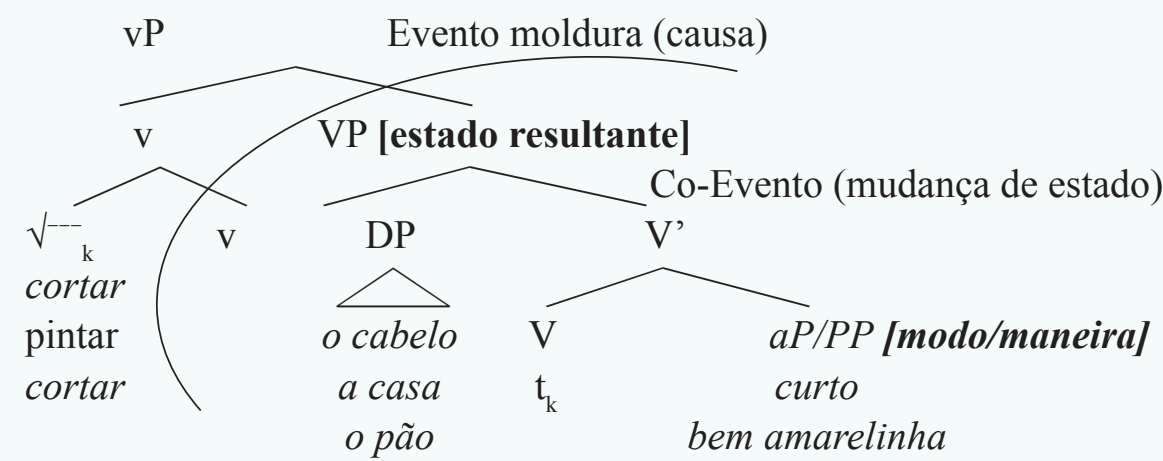

$$
\text { em fatias }
$$

(cf.: Barbosa 2012:200)

Dessa forma, fica garantida a impossibilidade de construções resultativas em PB, fato empiricamente desejável. Essa distinção é descrita pelo parâmetro de emolduração (cf.: (78)), adaptado de Barbosa (2012):

(78) Parâmetro de emolduração (revisado)

A denotação do traço de [modo/maneira] ocorre:

$\{\mathrm{Em} \mathrm{V}\}=$ inglês, holandês, alemão...

$\{\mathrm{Em} v\}=\mathrm{PB}$, espanhol, italiano...

(cf.: Barbosa 2012:201)

O parâmetro acima descreve a codificação sintática da distribuição dos traços do PB e do inglês de maneira empiricamente compatível com os fatos apresentados até aqui. Apenas no inglês é possível ter [modo/maneira] no verbo (V) e [estado resultante] simultaneamente no co-evento ${ }^{17}$. A única configuração para esses dois traços no co-evento no PB gera, obrigatoriamente, a modificação do estado resultante presente nas pseudo-resultativas do PB (cf.: (77), acima), justificando a semântica de mudança de estado nas pseudo-resultativas, como visto nos resultados dos testes apresentados na seção 4.1.

As OARs, por sua vez, trazem outra diferença nas relações de emolduração, bem como em sua configuração estrutural. Nessas sentenças, os traços de mudança de estado e de estado resultante acabam expressos sob domínio do PP adjunto, um satélite (79).

17. A versão anterior do parâmetro, extraída de Barbosa (2012), fez com que dois dos pareceristas questionassem a validade da proposta, e que houvesse uma conexão entre a discussão aqui apresentada e o Parâmetro de Composição, de Snyder (1995 et seq.). Por conta da ausência da bibliografia do autor na versão avaliada, não foi possível aos pareceristas consultarem Barbosa (2012), que defende exatamente a desvinculação do Parâmetro de Composição das construções resultativas. Por motivos de espaço, este artigo remete o leitor a Barbosa (2012) e a discussão lá apresentada. 
(79) Representação estrutural das OARs

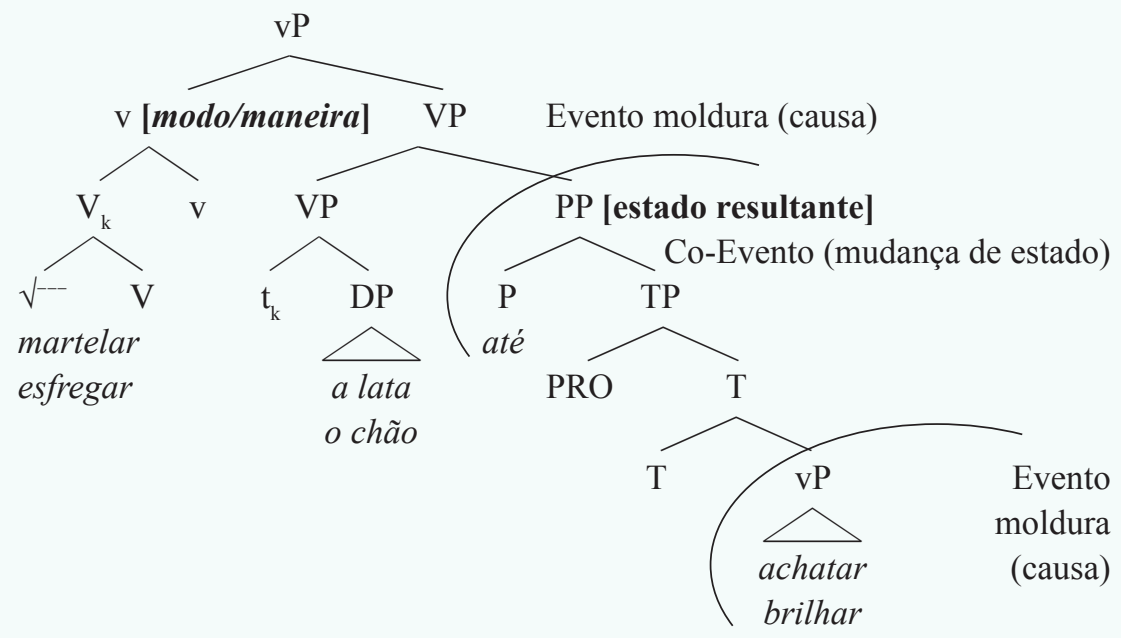

Por ocorrer em $v$, o traço de [modo/maneira] do PB sempre denota relação de causa indireta com o estado resultante - o estado denotado pelo PP adjunto decorre do evento descrito pelo VP, e não somente da ação verbal (martelar a latalesfregar o chão).

É importante notar que as sentenças transitivas simples no $\mathrm{PB}$ não apresentam correspondente morfossintático para denotar um eventual traço de [modo/maneira] no co-evento nos casos em que não há um predicado secundário para comportá-lo. A representação para sentenças transitivas pode ser vista em (80), abaixo ${ }^{18}$.

(80) Representação estrutural de sentenças transitivas canônicas no PB

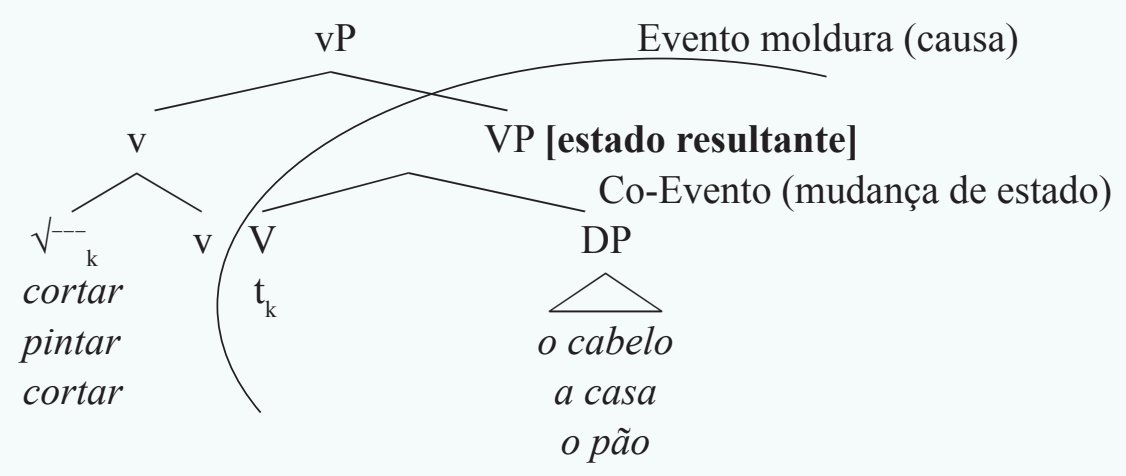

(cf.: Barbosa 2012:200)

Distinguir as estruturas pseudo-resultativas das OARs decorre não apenas da necessidade empírica mostrada nas seções 4.1 e 4.2: garantir duas estruturas

18. A estrutura transitiva simples para o inglês seria idêntica à do $\mathrm{PB}$, denotando o estado resultante na combinação entre verbo e objeto. A única diferença seria a presença do traço de [modo/maneira] em V (cf.: (78), acima). 
diferentes para cada um dos fenômenos do PB explicaria por que apenas nas OARs aparece a leitura de reiteração da ação:

Uma última observação, que favorece nossa análise sobre as resultativas infinitivas, vem do fato de Barbosa (2008, nota 3) apontar a existência de uma leitura de intensidade nas resultativas do inglês. Tal leitura parece ser garantida nas resultativas infinitivas justamente pela presença da preposição "até".

\section{(32) a. João bebeu até cair. \\ b. Maria cantou até cansar.}

Nos dois casos, há claramente uma leitura de intensidade na realização dos eventos de beber e cantar por parte de João e Maria. Essa leitura é evidenciada pela presença dos adjuntos nucleados por "até", que parece exigir um contexto em que os eventos de beber e cantar tenham durado um certo tempo. Por essa razão, a sentença em (32a) não parece ser adequada se João bebeu apenas um grande gole de tequila e caiu. Nesse caso, diríamos que "João bebeu e caiu", e não "até cair". (Bertucci 2014:639)

De fato, cortar o cabelo até ficar curto não é uma inferência decorrente da expressão cortar o cabelo curto; da mesma forma, hammer the metal flat ("martelar o metal plano") não ocorre, necessariamente, com uma única martelada. Resultativas genuínas e OARs compartilham essa característica pelo fato de um predicado secundário introduzir o estado resultante, o que garante a modalização - e, consequentemente, a leitura de intensidade - do verbo, enquanto pseudo-resultativas carregam essa modalização no predicado secundário.

Outra motivação para a distinção estrutural entre pseudo-resultativas e OARs - e para a semelhança entre estas e resultativas genuínas - se dá pela semântica dos verbos participantes nessas construções: OARs são formadas com verbos de atividade. Como aktionsart é composicional, o aspecto do evento é alterado pelo adjunto (télico). Esse é um fato desejável, pois nessas orações adjuntas, assim como nas resultativas, objetos de plural $n u$ removem a telicidade do VP:

(81) John sang babies asleep for hours last night. John cantou bebês adormecido por horas última noite 'John acalentou bebês até adormecer(em) por horas na noite passada' 
(82) João martelou latas até achatar por dias a fio/*em um instante.

(83) Maria esfregou pisos até brilharem por muitas semanas/*em poucos dias.

A autonomia do PP em (79), acima, explicaria a diferença de interpretação do objeto em (67), acima - o co-evento só pode denotar mudança de estado e estado resultante; se o verbo infinitivo das OARs denota causa, a estrutura eventiva é diferente do inglês. Isso explica o fato de que, quando o PRO da sentença em (67), acima, é interpretado como o sujeito da sentença principal, a leitura restitutiva deixa de ser possível.

\title{
6. Evidência adicional: construções seriais resultativas
}

O critério da mono-oracionalidade pode ser considerado estipulativo: por que a estrutura em (79), acima, não seria um exemplar de resultatividade sintática? Talmy $(2009,2012)$ afirma que construções com verbos seriais e construções polissintéticas também fazem parte da discussão de emolduração, e são evidência contra emolduração equipolente (equipollent framing, cf.: Slobin 2004, Croft et al. 2008). Talmy propõe que o segundo verbo das construções seriais de algumas línguas possa ser interpretado como um adjetivo ou preposição (partículas) - caso dos verbos adjetivais do edo:

\begin{abstract}
Ademais, como argumento semântico, nós observamos que ao contrário dos verbos de ação do Edo, verbos adjetivais, que têm sido chamados erroneamente de adjetivos, dão as qualidades inerentes de atributos de pessoas e objetos que co-ocorrem com eles. ${ }^{19}$

(Qmqruyi 1986:285)
\end{abstract}

Seguindo Halle; Marantz (1993), Marantz (1997), Hale; Keyser (2002), seria possível sugerir que as raízes do edo sejam categorialmente neutras, podendo ocorrer como verbos ou adjetivos. Essa é a proposta de Baker (2003:21):

Em contraste a teorias que atribuem um caráter particularmente modificacional aos adjetivos (Croft 1991; Hengeveld 1992; Bhat 1994), eu defendo que adjetivo é essencialmente a categoria "default". Ela aparece em uma classe não natural de ambientes em que nem um nome ou um verbo apareceriam, incluindo a posição de modificação atributiva, o complemento de um núcleo de grau, na posição de predicado secundário resultativo e em posições adverbiais. No apêndice, eu defendo que adposições estão completamente fora do sistema de

19. "Moreover, on semantic grounds, we observe that unlike Edo action verbs, adjectival verbs, which have been erroneously called adjectives, give the inherent qualities or attributes of persons and objects that co-occur with them." 
categorias; ao invés disso, padrões de incorporação mostram que eles são núcleos funcionais que criam adjuntos de vários tipos. $^{20}$

No caso do edo, é fácil comprovar empiricamente a mono-oracionalidade nas resultativas (cf.: Stewart 1998). Nessa língua, um advérbio flexional (I-type) como giégié não pode ocorrer entre os dois verbos da construção serial resultativa (84), mas é aceito na construção serial de consequência (85):
(84) *Òzó$$
\text { sùá ò̀gó }
$$$$
\text { empurrar garrafa }
$$$$
\text { gié! gié }
$$$$
\text { rapidamente }
$$$$
\text { dé }
$$
'Ozo derrubou a garrafa rapidamente empurrando-a'
(85) Òzó dùnmwún èmà gié!gié khién
Ozo esmagou inhame rapidamente vender
'Ozo esmagou o inhame para vendê-lo rapidamente'

(Stewart 1998:34)

Sandalo (1995) também mostra que construções seriais do kadiwéu combinam um verbo de classe aberta e uma raiz com propriedades semelhantes às de preposições (cf.: (86), abaixo), o que corrobora a ideia de que o segundo verbo das construções seriais pode se comportar como um predicado secundário em alguns contextos, como construções seriais resultativas. Afinal, preposições tendem a se comportar como satélites, e não formariam outro domínio eventivo/ oracional (cf.: (79), acima).

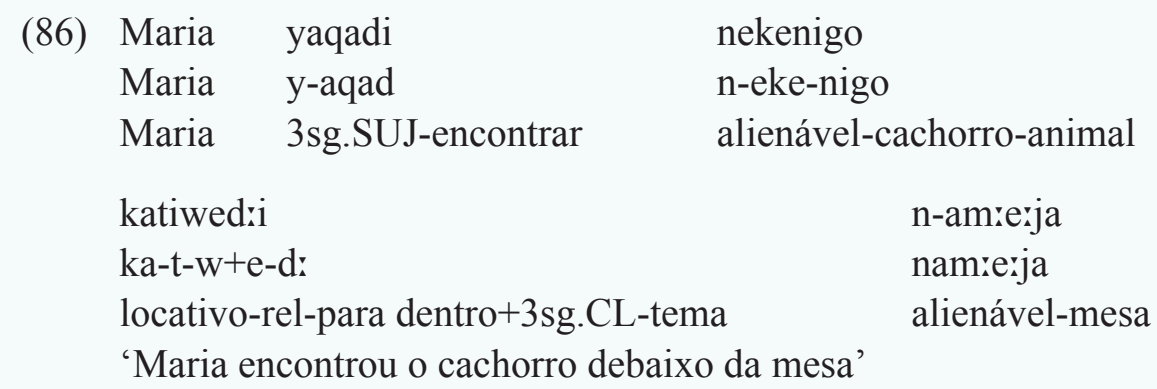

(Sandalo 1995:94)

Em suma, línguas com construções resultativas genuínas (seriais ou não) parecem fazer parte de um grupo tipológico diferente do PB - o de línguas emolduradas pelos satélites (cf.: Talmy 2000).

20. "In contrast to theories that attribute a particular modification character to adjectives (Croft 1991; Hengeveld 1992; Bhat 1994), I hold that adjective is essentially the "default" category. It appears in a nonnatural class of environments where neither a noun nor a verb would do, including the attributive modification position, the complement of a degree head, resultative secondary predicate position, and adverbial positions. In the appendix, I argue that adpositions are not part of the system of lexical categories at all; rather, incorporation patterns show them to be functional heads that create adjuncts of various kinds." 


\section{Considerações finais}

Este artigo buscou esclarecer - e argumentar contra - algumas das concepções utilizadas para defender a existência de construções resultativas no PB. É importante lembrar que a ideia de construção remonta aos primórdios da Gramática Gerativa, quando uma construção era o produto de operações transformacionais sobre uma sentença já formada. Essa noção, ao longo do tempo, passou a representar um fenômeno com propriedades sintáticas específicas, presente em uma ou mais línguas. Nesse sentido, a construção resultativa não é um fenômeno representado pelas possibilidades de combinação lexicais em sentenças do português. Porém, isso não significa que a expressão de estado resultante e modo/maneira de ação esteja indisponível nessa língua esse amálgama de traços só não está disponível em PB na configuração sintática mono-oracional, em vP único. Convém relembrar as palavras de Jakobson (1969:69): "As línguas diferem essencialmente naquilo que devem expressar, e não naquilo que podem expressar".

A argumentação deste trabalho não buscou, em momento algum, invalidar as hipóteses defendidas pelos demais autores que abordaram os fenômenos do PB considerados por eles construções resultativas - seja as pseudo-resultativas, seja as OARs. Bertucci (2014) tem razão quando afirma que as OARs “[...]têm os mesmos efeitos semânticos que aquelas apresentadas em inglês" (2014:641). A denotação de estado resultante nas sentenças das línguas naturais é universal, como já afirmava Talmy $(1985,1991,2000)$, quando propõe uma universalidade da conceitualização do evento. A questão é: o lugar em que os traços relevantes para esses (sub)eventos se manifestam é o que distingue as línguas em suas estruturas sintáticas.

Desse modo, pode-se dizer que construções resultativas são (i) estruturas mono-oracionais, (ii) que denotam o estado resultante no seu predicado secundário (AP ou PP), (iii) o modo/a maneira da ação é denotado pelo verbo $\mathrm{V}$, não $v-$, e não no predicado secundário. Essa construção específica, baseada nestes critérios, não está disponível na possibilidade de combinações sintáticas do PB. Essa conclusão depende da premissa de que predicados complexos são formados dentro de um mesmo vP, e que [modo/maneira] na raiz verbal só ocorrem em línguas do tipo de emolduração do inglês (cf.: (78), acima).

Por fim, a manifestação de construções pseudo-resultativas no PB mostra que a expressão de estruturas semânticas é universal, enquanto as manifestações sintáticas dessas estruturas são determinadas parametricamente, baseadas em restrições morfossintáticas - uma conclusão desejável quando observados os modelos de variação atuais, que dizem que variação paramétrica é morfossintática, e não semântica (Berwick; Chomsky 2011, Sigurðsson 2011). 
Recebido em: 07/12/2016

Aprovado em: 07/07/2017

Email:

Julio William Curvelo Barbosa juliowbarbosa@gmail.com

\section{Referências}

bAKER, Mark. C. 2003. Lexical Categories: Verbs, Nouns, and Adjectives. Cambridge: Cambridge University Press.

BARBOSA, Julio. 2008. A estrutura sintática das chamadas 'construções resultativas em $P B$ '. Dissertação de Mestrado. São Paulo: Universidade de São Paulo.

2009. Are the resultative constructions in BP real resultatives? Revista Argentina de Lingüistica, 1: 87-100.

2012. Variação paramétrica em predicados complexos e nomes compostos: um estudo translinguístico. Tese de Doutorado. São Paulo: Universidade de São Paulo.

BECK, Sigrid. 2005. There and back again: a semantic analysis. Journal of Semantics 22: 3-51.

BERTUCCI, Roberlei. 2014. Construções resultativas infinitivas em português brasileiro. Alfa 59,3: 623-644.

BERWICK, Robert C.; CHOMSKY, Noam. 2011. The biolinguistic program: The current state of its development. In: DI SCIULLO, Anna Maria; BOECKX, Cedric. (Eds.). The Biolinguistic Enterprise: New Perspectives on the Evolution and Nature of the Human Language Faculty. Oxford: Oxford University Press.

BISOL, Leda. 1975. Predicados complexos do português; uma análise transformacional. Porto Alegre: Editora da UFRGS.

CARRIER, Jill; RANDALL, Janet H. 1992. The argument structure and syntactic structure of resultatives. Linguistic Inquiry 23: 173-234.

FOLTRAN, Maria José G. D. 1999. As construções de predicação secundária no português do Brasil: aspectos sintáticos e semânticos. Tese de Doutorado. São Paulo: Universidade de São Paulo.

HALE, Ken; KEYSER, Samuel J. 1993. On Argument Structure and the Lexical Expression of Syntactic Relations. In: HALE, Ken; KEYSER, Samuel J. (Eds.). The View from Building 20: Essays in Linguistics in Honor of Sylvain Bromberger. Cambridge: The MIT Press.

1998. A Response to Fodor and Lepore, 'Impossible Words?'. Linguistic Inquiry, 30(3): 453-466.

2002. Prolegomenon to a Theory of Argument Structure. Cambridge: The MIT Press. 
HARLEY, Heidi. 2007. The bipartite structure of verbs cross-linguistically. In: SILVA, Thaïs C.; MELLO, Heliana. (Eds.). Conferências do V Congresso Internacional da Associação Brasileira de Linguística. Belo Horizonte: FALE/ UFMG.

HOEKSTRA, Teun. 1988. Small clause results. Lingua 74: 101-139.

ILARI, Rodolfo. 2006. Expressão do resultado e construções resultativas numa reflexão de Lúcia Lobato. Mimeo.

JAKOBSON, Roman. 1969. Linguística e comunicação. São Paulo: Cultrix.

KNÖPFLE, Andrea. 2010. A estrutura sintática das resultativas adjetivais no alemão: uma proposta a partir de Kratzer (2005). Dissertação de Mestrado. Curitiba: Universidade Federal do Paraná.

2014. Resultativas em línguas ocidentais germânicas: generalizações descritivas, descobertas empíricas e questões analíticas. Tese de Doutorado Curitiba: Universidade Federal do Paraná.

KRATZER, Angelika. 2004. Building resultatives. In: MAIENBORN, Claudia.; WLLSTEIN-LEISTEN, Angelika. (Eds.). Event arguments in syntax, semantics, and discourse. Tübingen: Niemeyer.

LANDAU, Idan. 2003. Unaccusatives, Resultatives, and the Richness of Lexical Representations. Introduction to Syntax, 24.951, MIT, Fall 2003. Handout.

LEITE, Marcelo. A. 2006. Resultatividade: um estudo das construções resultativas em português. Tese de Doutorado. Rio de Janeiro: Universidade Federal do Rio de Janeiro.

LEVIN, Beth; RAPPAPORT HOVAV, Malka. 1995. Unaccusativity: at the syntaxlexical semantics interface. Cambridge: The MIT Press.

LEVINSON, Lisa. 2006. Arguments for Pseudo-Resultative Predicates. 27p. Disponível em http://ling.auf.net/lingbuzz/000315/v1.pdf. Acesso em 16/11/2016.

LOBATO, Lucia. 2004. Afinal, existe a construção resultativa em português? In: NEGRI, Lígia; FOLTRAN, Maria José; PIRES DE OLIVEIRA, Roberta. (Eds.). Sentido e significação: em torno da obra de Rodolfo Ilari. São Paulo: Contexto.

MARANTZ, Alec. 1997. No Escape from Syntax: Don't Try Morphological Analysis in the Privacy of Your Own Lexicon. University of Pennsylvania Working Papers in Linguistics 4,2;14: 201-225. Disponível em

http://repository.upenn.edu/pwpl/vol4/iss2/14. Acesso em 18/11/2016.

MARCELINO, Marcello. 2000. Construções Resultativas em Português e em Inglês: Uma Nova Análise. Dissertação de Mestrado. São Paulo: Pontifícia Universidade Católica de São Paulo.

2007. O Parâmetro de Composição e a Aquisição/Aprendizagem de L2. Tese de Doutorado. Campinas: Universidade Estadual de Campinas.

. 2014. Resultativas em português brasileiro. Veredas 18: 121-137.

MATEU, Jaume. 2000. Syntactically-based Lexical Decomposition: The Case of Climb Revisited. Proceedings of the Twenty-Sixth Annual Meeting of the 
Ter estado resultante não é ter construção resultativa: predicados secundários pseudo-resultativos e orações adjuntas de resultado no português brasileiro

Berkeley Linguistics Society: General Session and Parasession on Aspect. 187-198.

. 2001. Small clause results revisited. ZAS Papers in Linguistics 26: 127-152.

MATEU, Jaume; RIGAU, Gemma. 1999. Universals of Lexical-Syntactic Typology and Parametric Variation. GLOW Newsletter 42: 38-39.

NEELEMAN, Ad; VAN DE KOOT, Hans. 2002. Bare Resultatives. The Journal of Comparative Germanic Linguistics 6 (1): 1-52. Disponível em

https://iris.ucl.ac.uk/iris/publication/121246/1. Acesso em 08/11/2016.

OLIVEIRA, Cândido. 2013. A construção resultativa e sua representação por bilingues do par linguístico português do brasil e inglês. Dissertação de Mestrado. Belo Horizonte: Universidade Federal de Minas Gerais.

. 2014. Uma investigação sobre a aquisição das regras de formação da construção resultativa por bilíngues de alta proficiência do par linguístico português do Brasil e inglês. Letrônica 7,1: 66-85.

OLIVEIRA, Cândido; SOUZA, Ricardo. 2012. Uma exploração da aprendizibilidade da construção resultativa do inglês por bilíngues do par linguístico português do Brasil e inglês. Confluência 43,2: 242-260.

PARSONS, Terence. 1990. Events in the semantics of English: a study in subatomic semantics. Cambridge: The MIT Press.

QMQRUYI, Thomas O. 1986. Adjectives and adjectivalization processes in edo. Studies in African Linguistics 17: 283-302.

RECH, Núbia. 2007. A formação de construções resultativas no português brasileiro. Caderno de Estudos Linguísticos 49,1: 79-100.

ROTHSTEIN, Susan. 2000. Secondary predication and aspectual structure. ZAS Papers in Linguistics 17: 241-264.

SANDALO, Filomena. 1995. A Grammar of Kadiwéu. Tese de Doutorado. Pittsburgh: University of Pittsburgh.

SHIM, Ji Y.; DEN DIKKEN, Marcel. 2008. The tense of resultatives: The case of Korean. Proceedings of NELS 38: 337-351.

SIGURĐSSON, Halldór Ármann. 2011. Uniformity and diversity: A minimalist perspective. Linguistic Variation 11: 189-222.

SIMPSON, Jane. 1983. Resultatives. In: LEVIN, Lori; RAPPAPORT, Malka; ZAENEN, Annie. (Eds.). Papers in Lexical-Functional Grammar. Bloomington: Indiana University Linguistics Club.

SLOBIN, Dan. I. 2004. The many ways to search for a frog: Linguistic typology and the expression of motion events. In: STRÖMQVIST, Sven; VERHOEVEN, Ludo. (Eds.). Relating events in narrative: Typological and contextual perspectives. Mahwah: Lawrence Erlbaum Associates.

SNYDER, William. 1995. Language Acquisition and Language Variation: The Role of Morphology. Tese de Doutorado. Cambridge: The MIT Press.

STEWART, Osamuyimen T. 1998. The Serial Verb Construction Parameter. Tese de Doutorado. Montreal: McGill University. 
TALMY, Leonard. 1985. Lexicalization patterns: semantic structure in lexical forms. In: SHOPEN, Timothy (Ed.). Language Typology and Syntactic Descriptions, Vol. 3: Grammatical Categories and the Lexicon. Cambridge: Cambridge University Press.

1991. Path to Realization: A Typology of Event Conflation. Proceedings of the Seventeenth Annual Meeting of the Berkeley Linguistics Society 17: 480519 .

2000. Toward a cognitive semantics. Cambridge: The MIT Press.

2009. Main Verb Properties and Equipollent Framing. In: GUO; JianSheng; LIEVEN, Elena; BUDWIG, Nancy; ERVIN-TRIPP, Susan; NAKAMURA, Keiko; ÖZÇALIŞKAN, Şeyda. (Eds.). Crosslinguistic Approaches to the Psychology of Language: Research in the Tradition of Dan Isaac Slobin. Mahwah: Lawrence Erlbaum Associates.

. 2012. Main verb properties. International Journal of Cognitive Linguistics 3: $1-24$.

VENDLER, Zeno. 1957. Verbs and Times. The Philosophical Review 66,2:143160. Disponível em http://links.jstor.org/sici?sici=0031-8108\%28195704\%2 966\%3A2\%3C143\%3AVAT\%3E2.0.CO\%3B2-2. Acesso em 20/06/2017.

. 1967. Linguistics in Philosophy. Ithaca: Cornell University Press. 